\title{
Assessing the efficacy and safety of hydroxychloroquine as outpatient treatment of COVID-19: a randomized controlled trial
}

\author{
Ilan Schwartz MD PhD, Mari E. Boesen MSc, Graziela Cerchiaro PhD, Craig Doram BSc PEng, \\ Brett D. Edwards MD, Aravind Ganesh MD, Jamie Greenfield MPH, Scott Jamieson BScPT MPH, \\ Vikram Karnik MD, Carol Kenney RN, Rachel Lim MD, Bijoy K. Menon MD, Kwadwo Mponponsuo MD, \\ Sarah Rathwell MSc, Karla J. Ryckborst RN, Breanne Stewart RN, Maryna Yaskina PhD, Luanne Metz MD, \\ Lawrence Richer MD, Michael D. Hill MD MSc; for the ALBERTA HOPE COVID-19 Collaborators
}

\section{Abstract}

Background: Identification of therapies to prevent severe COVID-19 remains a priority. We sought to determine whether hydroxychloroquine treatment for outpatients with SARS-CoV-2 infection could prevent hospitalization, mechanical ventilation or death.

\begin{abstract}
Methods: This randomized controlled trial was conducted in Alberta during the first wave of the COVID-19 pandemic without direct contact with participants. Community-dwelling individuals with confirmed SARS-CoV-2 infection (by reverse transcription polymerase chain reaction [RT-PCR] viral ribonucleic acid test) within the previous 4 days, and symptom onset within the previous 12 days, were randomly assigned to oral hydroxychloroquine or matching placebo for 5 days. Enrolment began Apr. 15, 2020. The primary outcome was the composite of hospitalization, invasive mechanical ventilation or death within 30 days. Secondary outcomes included symptom duration and disposition at 30 days. Safety outcomes, such as serious adverse events and mortality, were also ascertained. Outcomes were determined by telephone follow-up and administrative data.
\end{abstract}

Results: Among 4919 individuals with a positive RT-PCR test, 148 (10.2\% of a planned 1446 patients) were randomly assigned, 111 to hydroxychloroquine and 37 to placebo. Of the 148 participants, 24 (16.2\%) did not start the study drug. Four participants in the hydroxychloroquine group met the primary outcome (4 hospitalizations, 0 mechanical ventilation, 4 survived to 30 days) and none in the placebo group. Hydroxychloroquine did not reduce symptom duration (hazard ratio 0.77 , $95 \%$ confidence interval $0.49-$ 1.21). Recruitment was paused on May 22, 2020 , when a since-retracted publication raised concerns about the safety of hydroxychloroquine for hospitalized patients with COVID-19. Although we had not identified concerns in a safety review, enrolment was slower than expected among those eligible for the study, and cases within the community were decreasing. Recruitment goals were deemed to be unattainable and the trial was not resumed, resulting in a study underpowered to assess the effect of treatment with hydroxychloroquine and safety.

Interpretation: There was no evidence that hydroxychloroquine reduced symptom duration or prevented severe outcomes among outpatients with proven COVID-19, but the early termination of our study meant that it was underpowered. Trial registration: ClinicalTrials.gov, no. NCT04329611

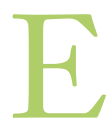
ighteen years ago, the severe acute respiratory syndrome (SARS) experience ${ }^{1-5}$ highlighted limited knowledge of early treatments for novel pandemic respiratory viruses. With the emergence of SARS-CoV-2, early experience in Wuhan, ${ }^{6}$ the Lombardy region of Italy ${ }^{7,8}$ and New York City ${ }^{9}$ demonstrated the need to suppress severe disease to prevent health system collapse. Hydroxychloroquine, derived from the centuries-old antimalarial medicine quinine, has broad antiviral effects and immunomodulatory properties, making it an attractive candidate to be repurposed for SARS-CoV-2 infection. The precise mechanisms of immunomodulation are uncertain, but the net result is inhibition of macrophage production of proinflammatory cytokines tumor necrosis factor (TNF)- $\alpha$ and

Competing interests: See the end of the article.

This article has been peer reviewed.

Correspondence to: Michael Hill, Michael.hill @ucalgary.ca CMAJ Open 2021. DOI:10.9778/cmajo.20210069 
interleukin (IL)-6. ${ }^{10}$ Hydroxychloroquine was explored as a putative agent for SARS in 2003, but that epidemic was contained before it could be adequately tested. In vitro effects on SARS-CoV-2 and enthusiasm from preliminary clinical investigations in COVID-19 resulted in its rapid, widespread, off-label use worldwide. ${ }^{11-16}$

We began a randomized placebo-controlled trial, leveraging the entire Alberta public health system infrastructure, to assess whether early hydroxychloroquine treatment in outpatients with SARS-CoV-2 infection would prevent progression to severe disease requiring hospitalization or mechanical ventilation, or resulting in death.

\section{Methods}

\section{Study design and setting}

This investigator-initiated, randomized, double-blind, placebocontrolled trial was conducted in Alberta, with enrolment beginning Apr. 15, 2020. Alberta has a population of 4.4 million, of whom about two-thirds live in urban settings. The protocol is available in Appendices 1, 2 and 3, available at www.cmajopen. ca/content/9/2/E693/suppl/DC1. An independent data and safety monitoring committee provided study oversight.

The trial was designed to determine whether early hydroxychloroquine treatment in community-dwelling individuals infected with SARS-CoV-2 prevented progression to severe disease. The publicly funded health system in Alberta is singularly responsible for testing, reporting and providing health services to all residents, permitting all individuals with confirmed SARS-CoV-2 infection to be identified. Alberta Health Services (AHS) staff obtained permission to share contact information with researchers after results of reverse transcription polymerase chain reaction (RT-PCR) tests were disclosed to infected individuals. Research coordinators then telephoned individuals who consented to be contacted and discussed the study, conducted screening, obtained informed consent and randomly assigned eligible participants by telephone.

To limit risk to study personnel and enable province-wide participation, all study interactions were conducted by telephone (including obtaining informed consent) or email. Screening was supported by access to the participants' provincial electronic health record, discussion with a study physician (as needed), and a telephone language translation service used during the calls. Calls, including the consent discussion, were recorded for quality assurance.

\section{Participants}

Adults with SARS-CoV-2 infection confirmed by RT-PCR from a nasopharyngeal or pharyngeal swab within the previous 4 days, with symptom onset within the previous 12 days and with at least 1 risk factor for severe disease (Appendix 1, Table S1) were eligible. Those who were hospitalized, pregnant or breastfeeding, unable to swallow pills or unable to comply with the medical regimen, or had used hydroxychloroquine, chloroquine, lumefantrine, mefloquine or quinine within the previous 30 days were excluded. Those at higher risk for arrhythmia secondary to hydroxychloroquine, including those concurrently using a drug that prolonged the corrected QT interval (QTc) and those with a modified Tisdale Risk Score of 7 or greater (Appendix 1, Table S2), were excluded.

We anticipated that enrolment could be completed between April and September 2020 given the rate of SARSCoV-2 infection, as we expected up to half of infected patients would participate.

\section{Intervention}

The hydroxychloroquine dose was $800 \mathrm{mg}$ orally in divided doses on day 1 followed by $200 \mathrm{mg}$ twice daily for 4 days, or identical matching placebo (12 tablets over 5 days). The study drug was delivered to participants' homes anywhere in the province by courier. Treatment initiation was confirmed by telephone or email.

\section{Outcomes}

The primary outcome was development of severe disease defined as the composite of hospitalization, invasive mechanical ventilation, or death within 30 days. Secondary outcomes included 1) days to COVID-19 recovery (symptom duration), defined as the number of days from randomization to symptom resolution; 2) disposition at 30 days, defined as recovered, ongoing symptoms but not hospitalized, hospitalized or deceased; and the proportion of participants 3) deceased, 4) admitted to ICU and 5) hospitalized, within 30 days. Safety outcomes were the proportion of participants with serious adverse events and the proportion with emesis.

\section{Data sources}

The primary outcome was obtained from administrative data, including vital statistics, hospital admission dates, intensive care admission and hospital discharge summaries. The Alberta electronic medical record includes Alberta Netcare, which encompasses all hospitalizations, diagnostic test results and outpatient pharmacy prescriptions. In addition, the routine administrative data from the Discharge Abstract Database, the provincial vital statistics registry and the National Ambulatory Care Reporting System were used.

Telephone interviews at 7 and 30 days, supported by review of electronic medical records, determined adherence, adverse events, disposition at 30 days, symptom duration and care during hospitalizations. Only serious adverse events and the predetermined adverse event of new or worsening emesis - considered because of the potential effect on adherence - were collected.

\section{Randomization and blinding}

Randomization was conducted using a custom-developed online tool to allow for dynamic randomization and allocation concealment. We used a minimal sufficient balance randomization tool to ensure balance on age, sex, risk status (binary variable based on age and other identified risks), days since symptom onset and provincial health zone (5 categories). ${ }^{17}$ Participants were randomly assigned 
to receive either hydroxychloroquine or placebo in a stochastically governed (not blocked) 2:1 ratio. We chose the 2:1 ratio to encourage participation by allocating a greater chance of receiving the active agent. Masking to allocation sequence was complete because randomization assignment was determined dynamically at randomization. All participants and the research team were blinded except for the research pharmacist and randomization website programmer.

\section{Statistical analysis}

The absolute effect size was estimated based on the Italian experience, assuming that up to $20 \%$ of the Alberta population (4.4 million) could acquire SARS-CoV-2 infection $(n=$ $840000)$, that $16 \%$ of those infected $(n=134400)$ could require hospitalization and that $3 \%$ of those infected $(n=$ 25200 ) could require invasive mechanical ventilation. We estimated the risk of severe disease to be at least twice as high in high-risk populations, so low-risk individuals were excluded. Assuming a $16 \%$ rate of the primary outcome, a risk ratio of 0.65 , with $2: 1$ randomization and $85 \%$ power, we estimated that 1446 evaluable patients with complete followup were required ( $n=482$ placebo; $n=964$ active treatment).

Comparisons were conducted under a superiority framework with a 2 -sided level of 0.05 . Secondary analyses followed a prespecified protected hierarchy; adjustments were not made for multiplicity. Treatment effects were reported with $95 \%$ confidence intervals (CIs). The intention-to-treat (ITT) population included all randomized participants. The perprotocol population included participants who were adherent to the treatment, defined as taking 10 or more of 12 tablets. The safety population consisted of participants who took any study drug.

We compared the proportion of participants in each treatment group who reached the primary outcome using the Fisher exact test. Although analysis of symptom recovery originally stipulated a semi-competing risks model with a competing risk of death, this was not required as no deaths were observed. Days to symptom recovery was plotted using Kaplan-Meier curves, and a log-rank test was used to test the hypothesis that the recovery-free curves did not differ between treatment and placebo. We estimated hazard ratios for treatment from a Cox proportional hazard regression model. The proportional hazards assumption was assessed graphically and through statistical testing. ${ }^{18}$ We tested the proportion of participants with safety outcomes using the Fisher exact test.

For assessing symptom duration, participants who recovered before randomization or were asymptomatic were removed, as were those without follow-up at day 7 or day 30 whose symptoms at randomization were unconfirmed. Participants without recovery dates were censored at their last follow-up with a known disposition. When disposition was known only at randomization, participants were considered lost to follow-up for this outcome and censored at day 1 .

We used the statistical software SAS (SAS Institute Inc.) and R (R Core Team). Study data were collected and man- aged using REDCap electronic data capture tools hosted and supported by the Women and Children's Health Research Institute at the University of Alberta. ${ }^{19}$

\section{Ethics approval}

The trial was approved by health research ethics committees of the University of Calgary and the University of Alberta, and all participants provided informed consent.

\section{Results}

During the study period, 4919 individuals with a positive PCR test for SARS-CoV-2 were identified (Figure 1), and 1207 consented to being contacted. A total of 233 participants were screened, and 148 were randomized, 111 to hydroxychloroquine and 37 to placebo (Figures 1 and 2). Participant characteristics are provided in Table 1. Telephone translation services were required by $10.6 \%$ of those contacted and $8.1 \%$ of randomized participants (Appendix 1, Table S3).

Before starting treatment, 11 of 148 (7.4\%) of randomly assigned participants withdrew. Five participants discontinued treatment on investigator recommendation. Figure 2 shows adherence to treatment and to telephone follow-up. Administrative data collection was complete for 147 of 148 participants.

Recruitment was paused on May 22, 2020, when a sinceretracted publication ${ }^{20,21}$ raised concerns about the safety of hydroxychloroquine for hospitalized patients with COVID19. A safety review was triggered, and 5 patients taking the study drug were asked to discontinue. Although no safety concerns had been identified in our study, enrolment was slower than expected among those eligible for the study, and cases within the community were decreasing. Recruitment goals were deemed to be unattainable during this wave of infection, and the trial was not resumed.

\section{Outcomes}

In the ITT population, 4 of 147 (2.7\%) participants met the primary outcome (Table 2). All 4 were hospitalized, none required mechanical ventilation and all survived to 30 days. All 4 were randomized to hydroxychloroquine, but 1 never started treatment and 2 discontinued early. The difference between groups for the primary outcome was not significant (risk difference $3.6 \%, 95 \%$ CI $0.1 \%-7.1 \%$ ) whether the missing outcome from 1 participant was considered as meeting the end point or not, or if the analysis included only participants who took at least 1 dose of the study drug (data not shown).

Symptom duration from enrolment was assessed for 124 of 148 participants (Table 2). There was no evidence suggesting nonproportional hazards $(p=0.3)$, and the estimated hazard of symptom recovery for hydroxychloroquine was nonsignificant at 0.77 (95\% CI 0.49-1.21) compared with placebo (Figure 3). Other secondary outcomes in the ITT population are shown in Table 2. Results in the per-protocol population did not meaningfully differ (Appendix 1, Table S4). 


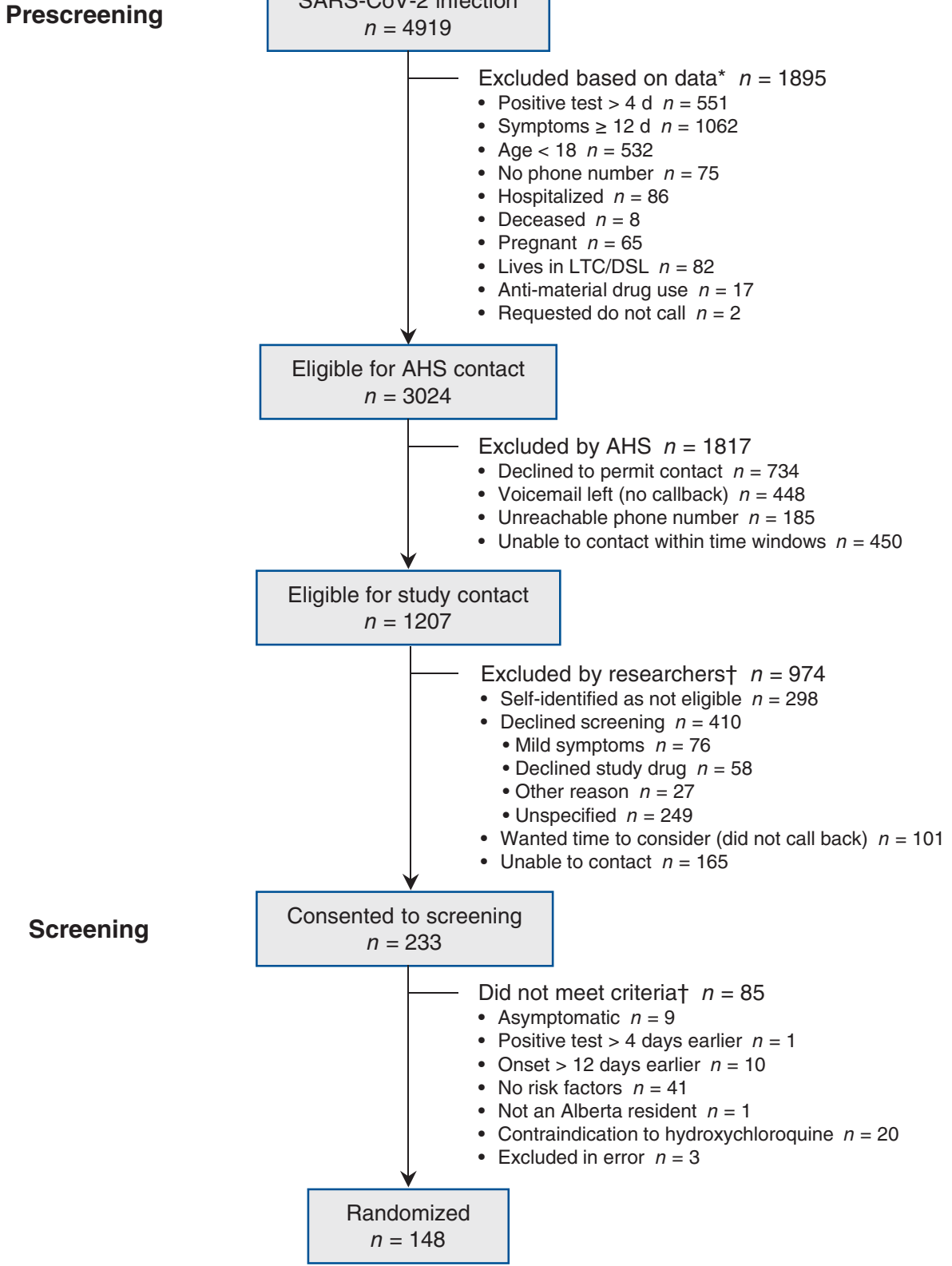

Figure 1: Screening process. Note: AHS = Alberta Health Services, DSL = designated supportive living, LTC = long-term care. ${ }^{*}$ Reasons are not mutually exclusive. $†$ Assigned to the first exclusion identified.

Although all safety events occurred in participants randomized to hydroxychloroquine, after pausing the trial, the data and safety monitoring committee reviewed unblinded data and identified no safety concerns. None of the 4 hospitalizations (Table 3), all for COVID-19 pneumonia, were judged to be related to treatment. One participant discontinued treatment after taking 2 tablets and was hospitalized 13 days after randomization. Another participant took 5 tablets, but emesis that was present before enrolment prevented starting the drug, and this participant was hospitalized 3 days after ran- domization. A third participant was hospitalized 1 day after randomization; treatment was completed in hospital. Five participants reported new or worsening emesis after initiating the study drug. One completed the study drug; 4 discontinued treatment within 3 days.

\section{Interpretation}

The trial recruited only $10 \%$ of the target sample size, stopping early because of a report on hydroxychloroquine safety 


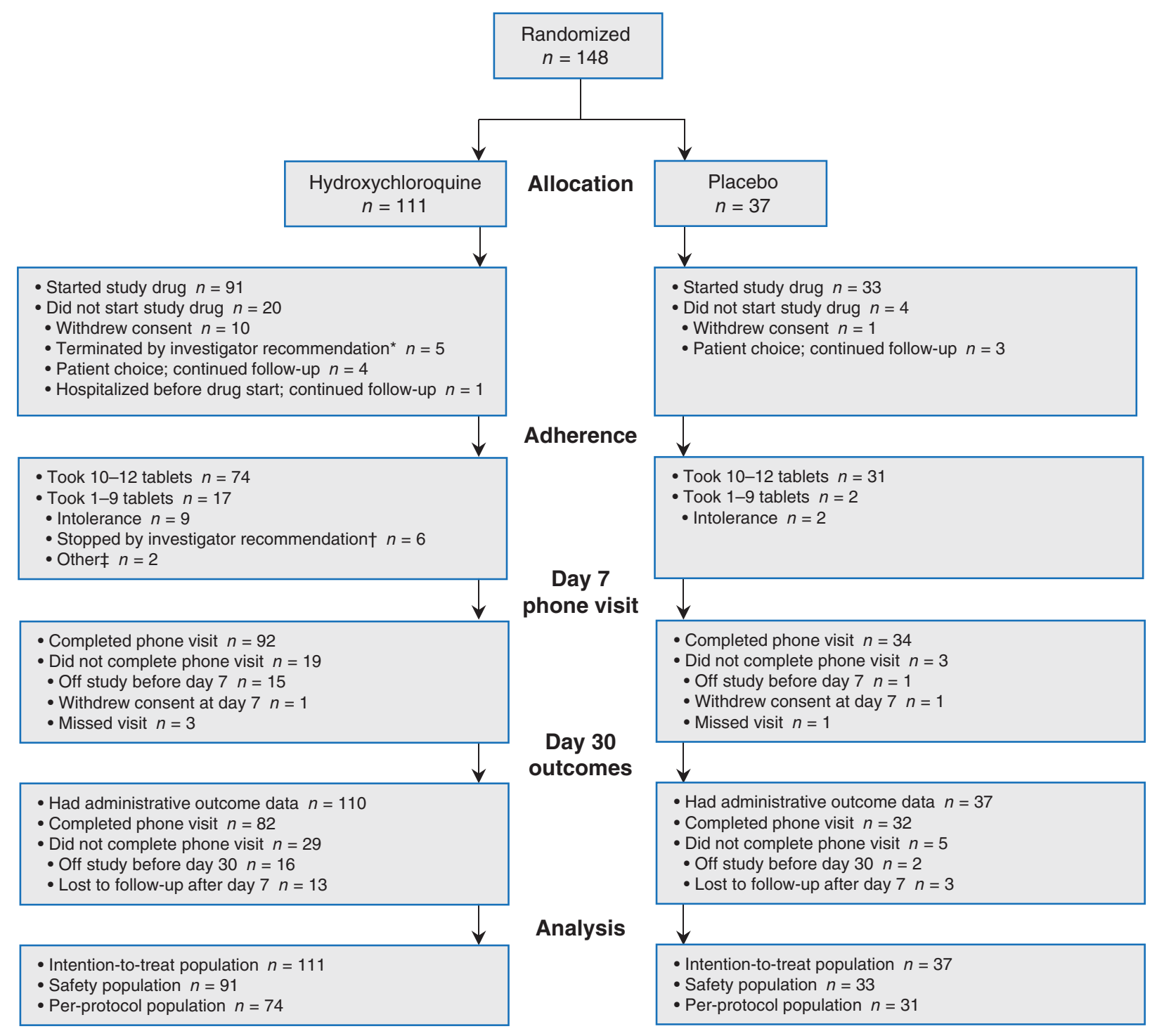

Figure 2: Consort diagram. *Five participants did not meet eligibility criteria: 3 had no risk factors for severe COVID-19 and 2 were taking a contraindicated medication. †One participant did not meet eligibility criteria (asymptomatic) and 5 participants were stopped for safety signal. $¥$ Two participants stopped study drug owing to COVID-19 symptoms that started before randomization.

(that was subsequently retracted $)^{20,21}$ and a rapid decline in disease prevalence coinciding with control of the first wave of the COVID-19 pandemic. There was neither a signal of treatment effect nor any safety signal observed, but the early termination of our study meant that it was underpowered. The lack of any early signal in our data is concordant with recently published results. ${ }^{2-33}$

The prevalence of the primary outcome was nonsignificantly lower than initially estimated, with trial participants having a lower nominal rate of hospitalization $(2.7 \%)$ than the broader Alberta population (4.5\%, 266/5878 during the same period) (data provided by Alberta Health). Individuals with
COVID-19 from long-term care facilities, where a high infection prevalence and mortality occurred but a higher safety risk was present, were not eligible for enrolment.

The choice to study hydroxychloroquine without adequate preclinical and early human data to estimate an effect size was a known risk that we accepted because of the public health urgency. Studies suggesting early efficacy of hydroxychloroquine for COVID-19 were biased by selection. ${ }^{11-14}$ Although initial in vitro studies suggested hydroxychloroquine was effective in inhibiting SARS-CoV-2, ${ }^{34,35}$ this was later refuted by studies that tested activity in more appropriate cell lines and animal models. ${ }^{36-38}$ 


\begin{tabular}{|c|c|c|}
\hline \multicolumn{3}{|c|}{$\begin{array}{l}\text { Table } 1 \text { (part } 1 \text { of } 2 \text { ): Baseline characteristics of participants } \\
\text { randomized to hydroxychloroquine or placebo }(n=148)\end{array}$} \\
\hline \multirow[b]{2}{*}{ Characteristic } & \multicolumn{2}{|c|}{ No. (\%) of participants* } \\
\hline & $\begin{array}{l}\text { Hydroxychloroquine } \\
\qquad n=111\end{array}$ & $\begin{array}{l}\text { Placebo } \\
n=37\end{array}$ \\
\hline $\begin{array}{l}\text { Age at randomization, yr, } \\
\text { mean } \pm \text { SD }\end{array}$ & $46.7 \pm 11.5$ & $46.9 \pm 11.0$ \\
\hline Sex, female & $46(41.4)$ & $20(54.1)$ \\
\hline $\mathrm{BMI}$, mean $\pm \mathrm{SD}$ & $28.3 \pm 7.3$ & $29.0 \pm 8.7$ \\
\hline \multicolumn{3}{|l|}{ Risk status $†$} \\
\hline Low & $41(38.0)$ & $12(32.4)$ \\
\hline High & $67(62.0)$ & $25(67.6)$ \\
\hline \multicolumn{3}{|c|}{ Common risk factors (present in $>10 \%$ ) } \\
\hline Age $\geq 40 \mathrm{yr}$ & $91(82.0)$ & $29(78.4)$ \\
\hline $\begin{array}{l}\text { Hypertension (receiving } \\
\text { medical treatment) }\end{array}$ & $29(26.1)$ & $12(32.4)$ \\
\hline $\begin{array}{l}\text { Diabetes (taking a } \\
\text { hypoglycemic or insulin) }\end{array}$ & $18(16.2)$ & $11(29.7)$ \\
\hline $\begin{array}{l}\text { Asthma (as per physician } \\
\text { diagnosis) }\end{array}$ & $12(10.8)$ & $8(21.6)$ \\
\hline Current cigarette smoker & $16(14.4)$ & $5(13.5)$ \\
\hline $\begin{array}{l}\text { Days from symptom onset to } \\
\text { randomization, } \ddagger \text { median } \\
\text { (IQR) }\end{array}$ & $7(5-8)$ & $6(6-9)$ \\
\hline \multicolumn{3}{|c|}{ Symptoms of COVID-19 since onsetł } \\
\hline $\begin{array}{l}\text { Fever }\left(\geq 37.5^{\circ} \mathrm{C} \text { if }\right. \\
\text { measured) }\end{array}$ & $54(49.1)$ & $20(54.1)$ \\
\hline Cough & $81(73.6)$ & $31(83.8)$ \\
\hline $\begin{array}{l}\text { Shortness of breath } \\
\text { (dyspnea) }\end{array}$ & $27(24.5)$ & $13(35.1)$ \\
\hline Chest tightness & $35(31.8)$ & $10(27.0)$ \\
\hline $\begin{array}{l}\text { Generally feeling unwell } \\
\text { (malaise) }\end{array}$ & $72(65.5)$ & $28(75.7)$ \\
\hline Sore throat & $49(44.5)$ & $20(54.1)$ \\
\hline $\begin{array}{l}\text { Muscle aches or pains } \\
\text { (myalgias) }\end{array}$ & $59(53.6)$ & $26(70.3)$ \\
\hline $\begin{array}{l}\text { Head cold or runny nose } \\
\text { (coryza) }\end{array}$ & $58(52.7)$ & 25 (67.6) \\
\hline $\begin{array}{l}\text { Decreased sense of taste } \\
\text { or smell (dysgeusia) }\end{array}$ & $60(54.5)$ & $29(78.4)$ \\
\hline Nausea & 39 (35.5) & 8 (21.6) \\
\hline Diarrhea & 35 (31.8) & $20(54.1)$ \\
\hline
\end{tabular}

For this trial, multiple new processes were rapidly developed and implemented. The challenges of identifying eligible participants in the community, procuring required technology and privacy access for coordinators to work remotely from home, scheduling coordinators, physicians, and AHS staff to work 7 days per week, obtaining verbal consent, the frequent need for language translation, arranging study drug delivery to remote areas 7 days per week, and monitoring adherence were evident early. Despite Alberta's aggressive
Table 1 (part 2 of 2): Baseline characteristics of participants randomized to hydroxychloroquine or placebo $(n=148)$

\begin{tabular}{|c|c|c|}
\hline \multirow[b]{2}{*}{ Characteristic } & \multicolumn{2}{|c|}{ No. (\%) of participants* } \\
\hline & $\begin{array}{l}\text { Hydroxychloroquine } \\
\qquad n=111\end{array}$ & $\begin{array}{c}\text { Placebo } \\
n=37\end{array}$ \\
\hline \multicolumn{3}{|c|}{ Provincial health zone } \\
\hline North Zone & $1(0.9)$ & 0 \\
\hline Edmonton Zone & $4(3.6)$ & 0 \\
\hline Central Zone & $1(0.9)$ & 0 \\
\hline Calgary Zone & $84(75.7)$ & $35(94.6)$ \\
\hline South Zone & $21(18.9)$ & $2(5.4)$ \\
\hline \multicolumn{3}{|c|}{ Reported race/ethnicity§ } \\
\hline White & $36(32.4)$ & $15(41.7)$ \\
\hline Black & $12(10.8)$ & 0 \\
\hline Asian & $53(47.7)$ & $19(52.8)$ \\
\hline Other & $10(9.0)$ & $2(5.6)$ \\
\hline \multicolumn{3}{|c|}{$\begin{array}{l}\text { Note: } B M I=\text { body mass index, } I Q R=\text { interquartile range, } S D=\text { standard } \\
\text { deviation. } \\
\text { *Unless stated otherwise. } \\
\text { †Risk status missing for } 3 \text { participants in the hydroxychloroquine group (no risk } \\
\text { factors). Low risk defined as age } 40-64 \text { with no other risk factors. High risk } \\
\text { defined as age } 18-64 \text { with another risk factor, or age } \geq 65 \text { regardless of other } \\
\text { risk factors. } \\
\text { fExcludes } 1 \text { participant in the hydroxychloroquine group who was asymptomatic. } \\
\text { \$Missing for } 1 \text { participant in the placebo group. }\end{array}$} \\
\hline
\end{tabular}

testing program, individuals often did not get tested early during their illness. When test results were reported, $22 \%$ $(1062 / 4919)$ were already out of the eligibility window. Under Alberta's Health Information Act, AHS, as the health data custodian, had to obtain permission from individuals to be contacted by the researchers, which caused an unavoidable delay. Only 40\% (1207/3024) agreed to be contacted. Language barriers were another challenge. The largest provincial outbreaks were in 2 meat-packing plants, where many workers spoke neither English nor French.

In our study, commonly reported reasons for declining enrolment were that the prospective participants did not feel sick enough or their symptoms were improving, they did not want to take medication, or they were worried about adverse effects. We speculate that other reasons included a lack of understanding of clinical research, no prior relationship with the researchers, and fear of treatment risk in the setting of a novel disease. These factors likely also contributed to the high proportion who never initiated treatment. Although remote enrolment was necessary owing to the short course of the illness and the requirement to protect study personnel from infection, it was difficult to recruit participants without face-to-face interaction or involvement of a care provider with whom they had a relationship.

An unforeseen external event that hampered this trial was the politicization of hydroxychloroquine. Widespread media attention resulted in polarizing views of the drug. The publication (and retraction owing to unverifiable data) of a large registry study ${ }^{20,21}$ that suggested unacceptable 


\begin{tabular}{|c|c|c|c|}
\hline \multirow[b]{2}{*}{ Outcome } & \multicolumn{2}{|c|}{ No. (\%) of participants* } & \multirow[b]{2}{*}{$p$ value } \\
\hline & $\begin{array}{l}\text { Hydroxychloroquine } \\
\qquad n=111\end{array}$ & $\begin{array}{c}\text { Placebo } \\
n=37\end{array}$ & \\
\hline Primary outcome†‡ & $4(3.6)$ & 0 & 0.69 \\
\hline \multicolumn{4}{|l|}{ Secondary outcomes } \\
\hline $\begin{array}{l}\text { Time to COVID-19 } \\
\text { recovery, d, median } \\
(95 \% \mathrm{Cl}) \S\end{array}$ & $14(10-20)$ & $12(7-18)$ & $0.3^{* *}$ \\
\hline Disposition at $30 \mathrm{~d} \ddagger$ & & & $\mathrm{NC}$ \\
\hline Recovered & $67(60.9)$ & $29(78.4)$ & \\
\hline $\begin{array}{l}\text { Ongoing symptoms, not } \\
\text { hospitalized }\end{array}$ & $23(20.9)$ & $6(16.2)$ & \\
\hline $\begin{array}{l}\text { Unknown, not } \\
\text { hospitalized or deceased }\end{array}$ & $20(18.2)$ & $2(5.4)$ & \\
\hline Mortality within $30 \mathrm{~d}$ & 0 & 0 & NC \\
\hline $\begin{array}{l}\text { Admission to ICU within } \\
30 \mathrm{~d} \neq\end{array}$ & $1(0.9)$ & 0 & NC \\
\hline Hospitalization within $30 \mathrm{~d} \ddagger$ & $4(3.6)$ & 0 & NC \\
\hline \multicolumn{4}{|c|}{$\begin{array}{l}\text { Note: } \mathrm{Cl}=\text { confidence interval, } \mathrm{ICU}=\text { intensive care unit, } \mathrm{NC}=\text { secondary outcomes were not compared } \\
\text { between groups following the prespecified protected hierarchy. } \\
\text { *Unless stated otherwise. } \\
\text { †Primary outcome: hospitalization, invasive mechanical ventilation or death within } 30 \text { days of randomization. } \\
\text { †Missing for } 1 \text { participant in the hydroxychloroquine group who declined consent for data collection after } \\
\text { they withdrew from the study. This participant was confirmed to be alive beyond } 30 \text { days when contacted } \\
\text { for re-consent. } \\
\text { \$Includes } 89 \text { participants in the hydroxychloroquine group and } 35 \text { in the placebo group with data on } \\
\text { symptoms duration. Participants who recovered before randomization or were asymptomatic ( } 1 \text { was } \\
\text { enrolled in error) were removed, as were } 12 \text { without follow-up at day } 7 \text { or day } 30 \text { whose symptoms at } \\
\text { randomization were unconfirmed. } \\
\text { १Two-sided Fisher exact test. } \\
\text { **Log-rank test. }\end{array}$} \\
\hline
\end{tabular}

risk of harm from hydroxychloroquine was a pivotal event. In the context of this negative public perception of hydroxychloroquine, emerging data from other randomized trials of hydroxychloroquine, the low and falling disease prevalence, recruitment challenges, and the realization that the target sample size was unattainable, the trial was permanently halted.

Despite setbacks, there were positive lessons that emerged. Enthusiastic participation from researchers donating their time and expertise, and rapid turnaround for study approval at Health Canada and at institutional ethics boards, and for funding decisions, were remarkable. Health Canada and Alberta research ethics boards embraced innovation to permit verbal-only consent documented by recording. Consortium-based funding and in-kind support came from the entire Alberta research community. Nationally, there were other trials addressing the same question and, in retrospect, more may have been achieved from better coordination at the national level.

Strengths of this study include the successful leverage of Alberta's integrated publicly funded health care system, widespread collaboration of researchers across 2 universities, and successful inclusion of non-English- or French-speaking individuals who are often excluded from trial participation. The study was a real-world example of a registry-based randomized controlled trial using centralized AHS data and involving AHS personnel in telephoning prospective participants. The contactless nature of the trial allowed enrolment throughout the province beyond the major referral centres.

\section{Limitations}

Although use of remote technology facilitated provincewide recruitment, it conversely resulted in inefficient recruitment and adherence. A similar approach was used in another trial assessing fluvoxamine for COVID-19. ${ }^{39}$ Inclusion of individuals' own primary care physicians may have improved recruitment, enhanced follow-up and accelerated knowledge translation. Provincial data systems could be enhanced by inclusion of a consent registry, or consent might have been obtainable at the time of testing, to avoid the need to obtain consent for research contact in the midst of a crisis. Including a research perspective into emergency preparedness planning could support the development of research strategies that would benefit crises resolution. Because the trial was terminated early, it was 


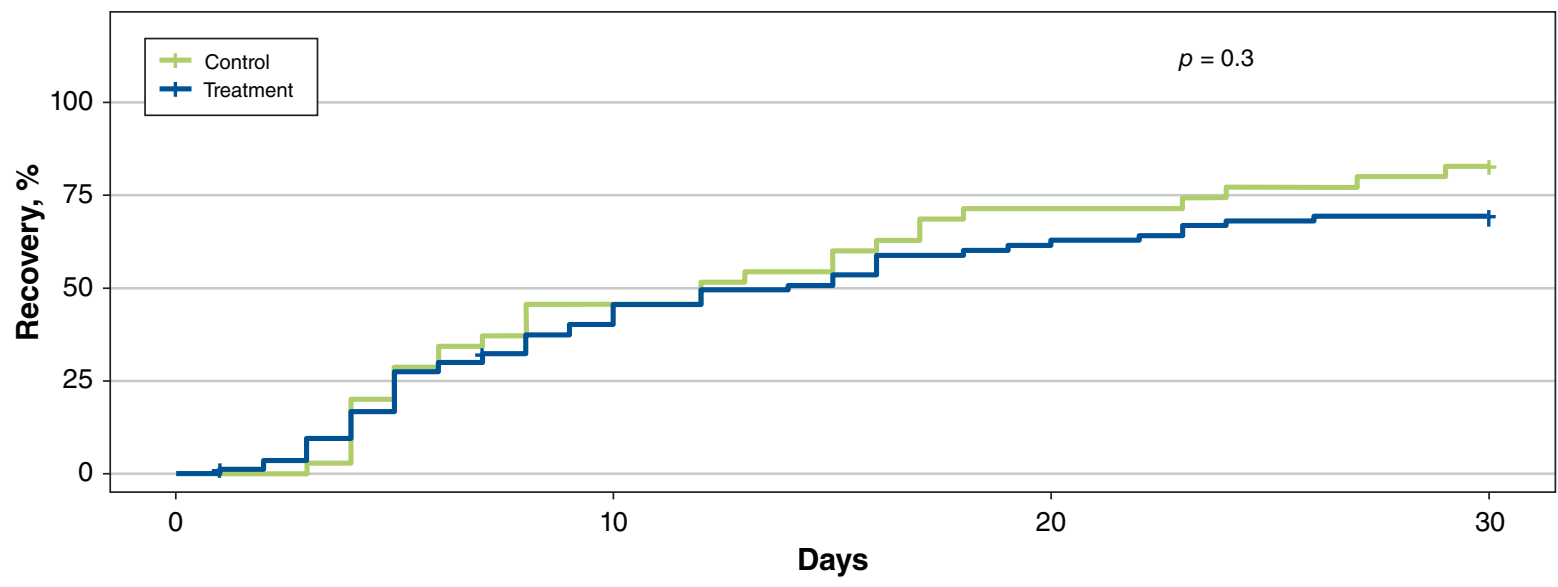

Figure 3: Participants who reached the outcome of symptom resolution over the course of 30 days after randomization in the intention-to-treat population $(n=124)$. The curves show the cumulative percentage of participants with symptom resolution over the course of 30 days after randomization. Estimates of the cumulative percentage recovered were calculated using Kaplan-Meier survival analysis. Participants were excluded if they recovered on or before randomization $(n=11)$, were asymptomatic $(n=1)$, or could not be confirmed symptomatic on randomization and had no follow-up at day 7 or day 30 and symptoms at randomization were unconfirmed $(n=12)$. Participants without recovery dates were administratively censored at the last follow-up with a known disposition. Participants were censored at day 1 if disposition was unknown at both day 7 and day 30 but they were confirmed to be symptomatic at randomization.

\begin{tabular}{|c|c|c|c|}
\hline \multicolumn{4}{|c|}{$\begin{array}{l}\text { Table 3: Safety outcomes in participants who took at least } 1 \text { tablet of } \\
\text { the study drug }(n=124)\end{array}$} \\
\hline \multirow[b]{2}{*}{ Safety outcome } & \multicolumn{2}{|c|}{ No. (\%) of participants } & \multirow[b]{2}{*}{$p$ value* } \\
\hline & $\begin{array}{l}\text { Hydroxychloroquine } \\
\qquad n=91\end{array}$ & $\begin{array}{l}\text { Placebo } \\
n=33\end{array}$ & \\
\hline SAE within $30 \mathrm{~d}$ & $3(3.3)$ & 0 & 0.6 \\
\hline Emesis within $30 \mathrm{~d}$ & $5(5.5)$ & 0 & 0.3 \\
\hline Mortality within $30 \mathrm{~d}$ & 0 & 0 & - \\
\hline Hospitalization within $30 \mathrm{~d}$ & $3(3.3)$ & 0 & 0.6 \\
\hline IMV or death within $30 \mathrm{~d}$ & 0 & 0 & - \\
\hline $\begin{array}{l}\text { Note: IMV = invasive mechanical } \\
\text { "Two-sided Fisher exact test. }\end{array}$ & tilation, $\mathrm{SAE}=$ serious ad & e event. & \\
\hline
\end{tabular}

underpowered, leading to low precision and an inability to draw conclusions about the treatment.

\section{Conclusion}

There was no evidence that hydroxychloroquine reduced symptom duration or prevented severe outcomes among outpatients with proven COVID-19, but the early termination of our study meant that it was underpowered. Despite its premature termination, this trial successfully introduced several methodological innovations in the execution of trials in Alberta. While the SARS-CoV-2 vaccines give reason for hope, challenges in production and distribution, vaccine hesitancy, and the emergence of variants mean that the original premise of our study to investigate therapies to prevent severe disease remains real and urgent.

\section{References}

1. Dwosh HA, Hong HHL, Austgarden D, et al. Identification and containment of an outbreak of SARS in a community hospital. CMA7 2003;168:1415-20.

2. Avendano M, Derkach P, Swan S. Clinical course and management of SARS in health care workers in Toronto: a case series. CMAJ 2003;168:1649-60.

3. Varia M, Wilson S, Sarwal S, et al.; Hospital Outbreak Investigation Team. Investigation of a nosocomial outbreak of severe acute respiratory syndrome (SARS) in Toronto, Canada. CMA7 2003;169:285-92.

4. Borgundvaag B, Ovens H, Goldman B, et al. SARS outbreak in the Greater Toronto Area: the emergency department experience. CMA7 2004;171:1342-4.

5. Poutanen SM, Low DE, Henry B, et al.; National Microbiology Laboratory, Canada; Canadian Severe Acute Respiratory Syndrome Study Team. Identification of severe acute respiratory syndrome in Canada. N Engl 7 Med 2003; 348:1995-2005. 
6. Pan A, Liu L, Wang C, et al. Association of public health interventions with the epidemiology of the COVID-19 outbreak in Wuhan, China. FAMA 2020;323:1915-23.

7. Grasselli G, Zangrillo A, Zanella A, et al. Baseline characteristics and outcomes of 1591 patients infected with SARS-CoV-2 admitted to ICUs of the Lombardy Region, Italy. 7AMA 2020;323:1574-81.

8. Grasselli G, Pesenti A, Cecconi M. Critical care utilization for the COVID19 outbreak in Lombardy, Italy: early experience and forecast during an emergency response. FAMA 2020;323:1545-6.

9. Richardson S, Hirsch JS, Narasimhan M, et al. Presenting characteristics, comorbidities, and outcomes among 5700 patients hospitalized with COVID-19 in the New York City Area. 7AMA 2020;323:2052-9.

10. Schrezenmeier E, Dörner T. Mechanisms of action of hydroxychloroquine and chloroquine: implications for rheumatology. Nat Rev Rheumatol 2020; 16:155-66.

11. Rosenberg ES, Dufort EM, Udo T, et al. Association of treatment with hydroxychloroquine or azithromycin with in-hospital mortality in patients with COVID-19 in New York State. 7AMA 2020;323:2493-502.

12. Gautret $\mathrm{P}$, Lagier J-C, Parola $\mathrm{P}$, et al. Clinical and microbiological effect of a combination of hydroxychloroquine and azithromycin in 80 COVID-19 patients with at least a six-day follow up: a pilot observational study. Travel Med Infect Dis 2020;34:101663.

13. Gautret $\mathrm{P}$, Lagier J-C, Parola $\mathrm{P}$, et al. Hydroxychloroquine and azithromycin as a treatment of COVID-19: results of an open-label non-randomized clinical trial. Int 7 Antimicrob Agents 2020;56:105949.

14. Lagier J-C, Million M, Gautret P, et al.; IHU COVID-19 Task force. Outcomes of 3,737 COVID-19 patients treated with hydroxychloroquine/ azithromycin and other regimens in Marseille, France: a retrospective analysis. Travel Med Infect Dis 2020;36:101791.

15. Pastick KA, Okafor EC, Wang F, et al. Review: Hydroxychloroquine and chloroquine for treatment of SARS-CoV-2 (COVID-19). Open Forum Infect Dis 2020; 7:ofaa130.

16. Shehab N, Lovegrove M, Budnitz DS. US hydroxychloroquine, chloroquine, and azithromycin outpatient prescription trends, October 2019 through March 2020. $\mathcal{F}$ AMA Intern Med 2020;180:1384-6.

17. Zhao W, Hill MD, Palesch Y. Minimal sufficient balance - a new strategy to balance baseline covariates and preserve randomness of treatment allocation. Stat Methods Med Res 2015;24:989-1002.

18. Grambsch PM, Therneau TM. Proportional hazards tests and diagnostics based on weighted residuals. Biometrika 1994;81:515-26.

19. Harris PA, Taylor R, Thielke R, et al. Research electronic data capture (REDCap) - a metadata-driven methodology and workflow process for providing translational research informatics support. 7 Biomed Inform 2009;42:377-81.

20. Mehra MR, Desai SS, Ruschitzka F, et al. Retracted: Hydroxychloroquine or chloroquine with or without a macrolide for treatment of COVID-19: a multinational registry analysis. Lancet 2020 May 22 [Epub ahead of print]. doi: 10.1016/S0140-6736(20)31180-6.

21. Mehra MR, Ruschitzka F, Patel AN. Retraction: Hydroxychloroquine or chloroquine with or without a macrolide for treatment of COVID-19: a multinational registry analysis. Lancet 2020;395:1820.

22. Boulware DR, Pullen MF, Bangdiwala AS, et al. A randomized trial of hydroxychloroquine as postexposure prophylaxis for COVID-19. $N$ Engl 7 Med 2020;383:517-25.

23. Borba MGS, Val FFA, Sampaio VS, et al. Effect of high vs low doses of chloroquine diphosphate as adjunctive therapy for patients hospitalized with severe acute respiratory syndrome coronavirus 2 (SARS-CoV-2) infection: a randomized clinical trial. 7AMA Netw Open 2020;3:e208857.

24. Mahévas M, Tran V-T, Roumier M, et al. Clinical efficacy of hydroxychloroquine in patients with covid-19 pneumonia who require oxygen: observational comparative study using routine care data. BM7 2020;369:m1844.

25. Tang $W$, Cao Z, Han $M$, et al. Hydroxychloroquine in patients with mainly mild to moderate coronavirus disease 2019: open label, randomised controlled trial. BM7 2020;369:m1849.

26. Rajasingham R, Bangdiwala AS, Nicol MR, et al. Hydroxychloroquine as preexposure prophylaxis for COVID-19 in healthcare workers: a randomized trial. Clin Infect Dis 2020 Oct. 17 [Epub ahead of print]. doi: 10.1093/cid/ciaa1571.

27. Mitjà O, Corbacho-Monné $\mathrm{M}$, Ubals $\mathrm{M}$, et al.; BCN PEP-CoV-2 RESEARCH GROUP. Hydroxychloroquine for early treatment of adults with mild COVID-19: a randomized-controlled trial. Clin Infect Dis 2020 July 16 [Epub ahead of print]. doi: 10.1093/cid/ciaa1009.

28. Mitjà $\mathrm{O}$, Corbacho-Monné $\mathrm{M}$, Ubals $\mathrm{M}$, et al.; BCN-PEP-CoV2 Research Group. A cluster-randomized trial of hydroxychloroquine for prevention of COVID-19. N Engl 7 Med 2021;384:417-27.

29. Skipper CP, Pastick KA, Engen NW, et al. Hydroxychloroquine in nonhospitalized adults with early COVID-19: a randomized trial. Ann Intern Med 2020;173:623-31.

30. Pan H, Peto R, Henao-Restrepo AM, et al. Repurposed antiviral drugs for COVID-19: interim WHO Solidarity Trial results. $N$ Engl 7 Med 2021; 384:497-511.

31. Cavalcanti AB, Zampieri FG, Rosa RG, et al. Coalition COVID-19 Brazil I Investigators. Hydroxychloroquine with or without azithromycin in mild-tomoderate COVID-19. N Engl F Med 2020;383:2041-52.
32. RECOVERY Collaborative Group; Horby P, Mafham M, Linsell L, et al. Effect of hydroxychloroquine in hospitalized patients with COVID-19. NEngl 7 Med 2020;383:2030-40.

33. Self WH, Semler MW, Leither LM, et al. Effect of hydroxychloroquine on clinical status at 14 days in hospitalized patients with COVID-19: a randomized clinical trial. $7 A M A$ 2020;324:2165-76.

34. Wang M, Cao R, Zhang L, et al. Remdesivir and chloroquine effectively inhibit the recently emerged novel coronavirus $(2019-\mathrm{nCoV})$ in vitro. Cell Res 2020;30:269-71.

35. Liu J, Cao R, Xu M, et al. Hydroxychloroquine, a less toxic derivative of chloroquine, is effective in inhibiting SARS-CoV-2 infection in vitro. Cell Discov 2020;6:16.

36. Hoffmann M, Mösbauer K, Hofmann-Winkler H, et al. Chloroquine does not inhibit infection of human lung cells with SARS-CoV-2. Nature 2020; 585:588-90.

37. Rosenke K, Jarvis MA, Feldmann F, et al. Hydroxychloroquine prophylaxis and treatment is ineffective in macaque and hamster SARS-CoV-2 disease models. 7CI Insight 2020;5:e143174.

38. Maisonnasse P, Guedj J, Contreras V, et al. Hydroxychloroquine use against SARS-CoV-2 infection in non-human primates. Nature 2020;585:584-7.

39. Lenze EJ, Mattar C, Zorumski CF, et al. Fluvoxamine vs placebo and clinical deterioration in outpatients with symptomatic COVID-19: a randomized clinical trial. $7 A M A$ 2020;324:2292-300.

Competing interests: Aravind Ganesh reports payments to his institution from the Canadian Institutes of Health Research (CIHR), the Canadian Cardiovascular Society, Alberta Innovates and Campus Alberta Neuroscience; consulting fees from MD Analytics, My Medical Panel, Atheneum, DeepBench and Research on Mind; meetings or travel support from American Academy of Neurology, Association of Indian Neurologists in America, American Heart Association and University of Calgary; and a provisional patent application for a system for patient monitoring and delivery of remote ischemic conditioning or other cuffbased therapies. He is a member of the editorial boards of Neurology: Clinical Practice, Neurology and Stroke. He has stock in SnapDx (patient monitoring and decision support technology), American Health Analytics (AHA Health Ltd.; patient monitoring) and TheRounds.com (physician social network). Bijoy Menon reports grants or contracts from CIHR, the Heart and Stroke Foundation of Canada and Alberta Innovates Health Solutions and patents from the United States Patent and Trademark Office on systems of triage in acute stroke. He is a member of and has stock in Circle NVI. Michael Hill reports that Apotex Pharma provided the drug and placebo for the current trial as an in-kind contribution to the study. He was the main contact with Apotex Pharma and has no other relationship with the company; there were no obligations attached to this donation of drug and placebo.

Affiliations: Division of Infectious Diseases (Schwartz, Mponponsuo), Department of Medicine, Faculty of Medicine and Dentistry, University of Alberta, Edmonton, Alta.; Alberta Strategy for Patient Oriented Research SUPPORT Unit (Boesen); Cumming School of Medicine (Boesen, Cerchiaro, Greenfield, Kenney, Ryckborst), University of Calgary; Section of Infectious Diseases (Edwards), Department of Medicine, and Department of Clinical Neurosciences (Doram, Ganesh, Karnik), Cumming School of Medicine, University of Calgary, Calgary, Alta.; Quality Management in Clinical Research Office (Jamieson, Stewart), University of Alberta, Edmonton, Alta.; Division of Respirology (Lim), Department of Medicine, Cumming School of Medicine, and Departments of Clinical Neurosciences and Community Health Sciences (Menon, Metz), Hotchkiss Brain Institute, Cumming School of Medicine, University of Calgary, Calgary, Alta.; Women and Children's Research Institute (Rathwell, Yaskina), and Department of Pediatrics (Richer), Faculty of Medicine and Dentistry, University of Alberta, Edmonton, Alta.; Departments of Clinical Neurosciences, Community Health Sciences, and Medicine (Hill), Hotchkiss Brain Institute, Cumming School of Medicine, University of Calgary, Calgary, Alta.

Contributors: Michael Hill, Luanne Metz, Lawrence Richer and Ilan Schwartz organized and provided senior leadership for the study. Ilan Schwartz, Luanne Metz, Lawrence Richer and Michael Hill wrote the manuscript. Statistical analyses were performed by Sarah Rathwell, Jamie Greenfield and Maryna Yaskina. All authors played key roles in study design, management, execution and critical revisions of the main manuscript. All authors gave final approval of the version to be published and agreed to be accountable for all aspects of the work. 
Members of the ALBERTA HOPE COVID-19 Collaborators: University of Alberta: Nasreen Ahmad, Giiovanni Ferrara, Alim Hirji, Scott Jamieson, Wendy Johnston, Meghan Linsdell, Jennifer McCombe, Kirstie McDermot, Jeffrey Narayan, Manasi Rajagopal, Sarah Rathwell, Leka Ravindran, Lawrence Richer, Ilan Schwartz, Maeve Smith, Penny Smyth, Breanne Stewart, Taylor Strei, Diane Turner, Kelsey Tymkow, Sylvia van Os, Tanya Voth, Rick Watts, Maryna Yaskina; University of Calgary: Katayoun Alikhani, Jolene Allan, Mohammad Almekhlafi, Geri Anderson, Elizabeth Baguley, Megan Barber, Mari Boesen, Graziela Cerchiaro Farah, Anne Elaine Clarke, Carla Coffin, John Conly, Shelagh B. Coutts, Craig Doram, Katerina Downing, Tom Durnin, Brett Edwards, Aurora Fifi-Mah, Amanda Fisher, Aravind Ganesh, Virginia Gonzalez, Jamie Greenfield, Sheilah Heal, Alexis K. Hill, Michael D. Hill, Jia Hu, Kelly Johnston, Vikram Karnik, Sharanjit Kaur, Carol Kenney, Sundus Khan, Adam Kirton, Linda Knox, Katrina Koger, Alex Lemnaru, Rachel Lim, Ayla Lo, Natalie Lopez-Leacock, Jennifer McKeage, Paul MacMullan, Bijoy K. Menon, Luanne Metz, Christopher Mody, Kwadwo Mponponsuo, Jessica Ng, Blessing Odia, Milada Pajevic, Remo Pannacione, Michael Parkins, Lorina Platon, Sandra Rivest, Martha Rojas Zavala, Melanie Rosario, Karla J. Ryckborst, Shahana Safdar, Kayla Sage, Karla Sanchez, Supriya Save, Lisa Semeniuk, Ranjani Somayaji, Ericka Teleg, Alain Tremblay, Gloria Roldan Urgoiti, Jan Veenhuyzen, Adam Zedde; Alberta Health Services: Jeffrey Bakal, Shelly Bayley, Lauren Bemister, Lisa Bilston, Megan Brierley, Karen Brooks, Candice Cameron, Gillian Catena, Paola Charland, Quentin Collier,
Ashley Drobot, Diana Horner, Reshma Karmali Alibhai, Daryl Lacombe, Marc Leduc, Delane Linkiewich, Debbie Mallet, Jatin Patel, Tristan Pidner, Pedro Reis, Mahnoush Rostami, Donna A. Smith, Michelle Stiphout, Nicole Tjepkema, Kelly van Camp, Rabia Wattoo, Becky Wong, Laurie Wright, Erik Youngson.

Funding: Calgary Health Trust, the University of Calgary, Alberta Innovates Health Solutions, Alberta Health Services and the Alberta Government provided funding. Hydroxychloroquine and matching placebo were provided by Apotex. Funders had no role in trial design, interpretation or publication decisions.

Content licence: This is an Open Access article distributed in accordance with the terms of the Creative Commons Attribution (CC BY-NC-ND 4.0) licence, which permits use, distribution and reproduction in any medium, provided that the original publication is properly cited, the use is noncommercial (i.e., research or educational use), and no modifications or adaptations are made. See: https://creativecommons.org/licenses/ by-nc-nd/4.0/

Data sharing: Primary deidentified data are available on reasonable request to the corresponding author.

Supplemental information: For reviewer comments and the original submission of this manuscript, please see www.cmajopen.ca/content/9/2/ E693/suppl/DC1. 